\title{
Workplace Spirituality: A Paradigm Shift to Ethics from Business
}

\author{
Subhadeep Mukherjee ${ }^{1}$, Soumendra Bhattacharjee ${ }^{2}$, Seema S. Singha ${ }^{3}$ \\ ${ }^{I}$ (Research Scholar, Centre for Management Studies, Dibrugarh University, Assam) \\ ${ }_{2}^{2}$ (Assistant Professor, Department of Management, B.I.T. Mesra, Kolkata Campus) \\ ${ }^{3}$ (Professor, Department of Commerce, Dibrugarh University, Assam)
}

\begin{abstract}
In today's business context, working spirituality has become most remarkable aspects of the organizational culture. The frequent conversation about spirituality at the workplace has uplifted the consciousness of the ethical responsibility among the corporate citizens. The sense of responsibility within the employees has been widely upgraded by the spiritual values, which directly made an impact on the overall development of the productivity as well as the organizational growth. However, the advancement of spirituality at workplace is extensively based on an individual responsibility towards the framework of a monastic work environment to enhance the spiritual consciousness and intellectual growth. In addition, to develop the ethical leaders in the workplace, the practice of spirituality is essential in daily organizational routine. According to 'Walter Earl Fluker' in his expert theory stated that spirituality demands that leaders should propagate and nurture the sense of self that perceive the interrelatedness of self, life or the sense of commonality.
\end{abstract}

KEYWORDS: consciousness, ethics, leaders, organization, spirituality, workplace.

\section{INTRODUCTION}

The traditional concept of 'Spirituality' is a widespread concept for many viewpoints. In general, it includes the sense of association to something bigger than ourselves, and it consistently in search for meaning in life, such as, it is cosmic human evidence about something that touches us all. In the $19^{\text {th }}$ Century, spirituality has been often distinct from religion and has become deeper conformed to subjective evidence and psychological development. The phase 'Spiritual' is now generally used in the background in which the phase 'religion' was suitably known. In Present days, spirituality generates inner-peace and forms a foundation for blessedness. Meditation and Similar related practices may help the practitioner to nurture his or her inner life and character. Swami Vivekananda' said that the greatest support to spiritual life is meditation, in meditation; we take off ourselves from all material estate and feel our divine presence. Nowadays, organizations suffer business losses, strained relationships with certain customers, distressed tempers, employee exits, delayed contracts, the list of woes are threatening to become overwhelming. These factors are leaving the employees demoralized and isolated. So, spirituality at work has become a tool for overcoming business problems. Over the last few years, spirituality has been identified as a significant area of research in the world of academia, to develop more substantial meaning to one's workplace. The spirituality approach seeks attention on the values, motivation, ethics, leadership, work-life balance and other important elements of an organization. Spirituality is also a regulation that focuses attention on practice, it is sometimes that we execute on priority to several act of awareness. Spirituality has to deal with the practical and daily encounter with others and at the same time focal point on being stranger and friends, collective and individual, demonic and divine. Spirituality can be contemplated from three major angles. They are - i) Spirituality is associated with the establishment of religion. ii) 'Self-Awareness' or 'Self-Actualization' by an individual or group that may or may not be aligned with an establishment of religious association or institution. iii) The spiritual ethical notions are related to ethics and values. Spirituality is basically a core of inner and social values of the ethical organization. This paper has been divided into eight parts: Introduction; Objective of the Study, Emerging Role of Spirituality at a workplace in 
Organizations Interdependence between Spirituality, Ethics, and Business, Characteristics of Spiritual Organizations, Spiritual Approaches Shaping the Workplace, Emergence of Virtuous Leaders, Conclusion.

\section{OBJECTIVE OF THE STUDY}

- To interpret the emerging role of spirituality at workplace.

- To understand the characteristics and approaches of spirituality in the workplace.

- To find out the inter-relationship of business, ethics and spirituality.

- To figure out the importance of ethical behavior within the managers.

\section{EMERGing Role OF SPIRITUALITY AT WoRKPlaCe}

Spirituality in the workplace was not considered by the classical model of management context, but presently the emergence of spirituality in the workplace identifies the desire, to find out the purpose of survival beyond their work-life. Classical Model was mostly centralized towards the accomplishment of the organizational goal efficiently without understanding the feelings toward others; furthermore employee's innerlife plays no role in the execution when the organization is the concern. Now days, Spiritual awareness can support an individual to understand better regarding the jobholder's working behavior with the current scenario. An important fundamental aspect of spirituality has been found by the Indian employees, which manifests direct implications about their performance of workplace, capabilities for legitimate decision making and task mindset towards ethical issues. We all love to work for a place where we both participate and deliberate our deep thoughts and divine feelings from our inner- soul. According to 'White', the two main reasons to propagate an environment for the humanistic life-force are to resolve fears and to tackle the internal strength of the employees. However, organizations have outbid each other to bring in highly genius and self-encouraged employees. Similarly 'Swami Vivekananda' also said that "Do not spend your energy in talking, but meditate in silence become a dynamo of spirituality" spirituality brings inner happiness and fulfillment in the employees satisfaction. Organizational and employees performance are positively affected by the spiritual values in which it allows an individual to evidence the consciousness at a rooted level, thereby enhancing their emotional intelligence. This can help an individual to enhance more determined and fascinating organizational vision, which can increase modernism or innovation. Similarly, employee commitment and teamwork can be enhanced by the spiritual values. Therefore, it has become essential to understand, what we mean by spiritually oriented personnel and how it can be quantified and developed within the organizational employees.

\section{INTER-RELATIONSHIP BETWEEN BUSINESS, ETHICS AND SPIRITUALITY}

'Ethics' is one's moralistic judgment's about right and wrong. Decisions seized within an organization may be contrived by the individual or groups, but whoever makes them will be motivated by the culture of the organization. The decision to enact ethically is the moral values. Employees must understand and think about the right course of action to uplift the organizational objective and goals parallel to raising of profits, reducing the labor turnover, maximizing the production, attracting more employees, reducing the cost of recruitment by maintaining the stability of the business within the ethical context. Spirituality and Profitability have become common privilege now a days. According to the growing body of research, the importing of Spiritual Values and ethics within the workplace has a positive impact towards increasing the productivity and profitability as well as employee retention, customer loyalty, and brand reputation. In addition, spirituality has become the explicit way to upgrade loyalty and build-up moral ethics at the workplace. Conversely expanding numbers of business people want their spirituality to be more than just faith and belief. -they want it to be practical and applied. Thus, the employers are visualizing spirituality as the medium to uplift the whole self-awareness to work-body, mind and spirit. For that aspect organizations have bottom lined the business over a tagline of "Do well by doing well". In today's scenario, a progression originated around the country, to lead the spiritual and 
ethical values into the business context. Now a day's people no longer focuses on the profit alone as the baseline, instead, they honor a "Tri-Base-Line," a pledge to "Planet, People, and Profit." In the early $20^{\text {th }}$ century there had been an accumulating attention on the life-force, spirituality and spiritual paradox in the Western Culture. Later this focal point got shifted to the modernized workplace inspired by enormous books and articles, which have been a patronizing role of spirituality in developing organization, economy and market, and subsequently the whole society. Spirituality can be described as the realization of natural human capabilities. It is basically about "enhancing a person in the fullest awareness." as one undoubtedly pursuit for the ultimate value. The core values of spirituality are the moral values of the intensity that they simulate. Interrelationship between business, ethics and spirituality is shown in fig.1.

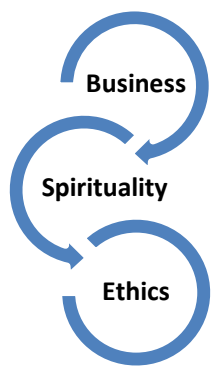

Fig.1: Inter-relationship between business, ethics and spirituality

\section{Characteristics Of Spiritual Organizations}

Now, the question comes to our mind how can we distinguish a spiritual organization from a nonspiritual organization? What are the distinct characteristics that differentiate a spiritual organization from others? Abiding by the wisdom of "Sanatan Dharma" and the findings of modern research, the characteristics of spiritual organization are as follows:-

- Solid Sensibility of Purpose: Organizational members know the purpose of existence of the organization they are working for and values of it.

- Focus on Personalized Development: Employees are needed to be nurtured to help them grow as they are the part of the organization; these also include the characteristics of Job security.

- Faith and Acceptance: The associations among the organizational members are portrayed by mutual faith, honesty, and acceptance.

- Job-holders Empowerment: Job-holders are granted to participate in work-related decisions that influence them, recommending a strong sense of delegation of authority.

- The Resistance to Employees' Interpretation: The cultural environment of the organization enables the employees to express their moods and feelings without any hesitation or fear.

\section{SPIRITUAL APPROACHES SHAPING THE WORKPLACE}

Nowadays, many people are pronouncing inspiration and fulfillment in their tasks by importing their spiritual values into the workplace. Spiritual Approaches are curving the contemporize of the today's' workplace. Such approaches are as follows:

- God-centered Approach: Spiritual associations or an organization has dedicated their time and resources to up-bring the God-centric spirituality at the workplace, mostly it seeks to strengthen jobholder's faith towards the God. This approach mainly focuses on widening the faith and approaching the helping hands to those in need. 
- Moralistic Approach: The moralistic approach to workplace spirituality emphasizes on nurturing the values that motivate us to be decent in our task, job or profession.

- Pragmatic Approach: This approach focuses on finding and conserving the meaning of our jobs. It also focuses on social involvement by conserving the valuable human aspect of work and interrupting the automate business practices by protecting which is meaningful and valuable for themselves and their families.

- Buddhist Approach: The approach of Buddhist is unique in its own way as it is based on exercising conscientious awareness meditation where specialists determine that in order to help others. Thus, Buddhist approach attempts with those who promotes charity, ethics and social involvement. Having control over their hearts and minds through meditation, Buddhists are open and willing to address work wakefully, courageously and authentically.

\section{EMERGENCE OF VIRTUOUS LEADERS}

Morality is an attitude, personality traits that enable us to act in a way that allows us to attend our human ability for moralistic excellence. They percolate our state of being and dispose us to action. The person of virtue is morally good in attitude. Virtue facilitates us to have an appropriate emotion and inner spirit as well as forwarding us to act in a virtuous way. Virtue flourishes through learning and exercise, after imitating such actions, they acquire good habits. The more virtuous the individuals are, the more morally upgraded they are. They will aim towards moral goods. The virtuous person will react easy in the situations that would be the test for the ordinary people to analyze the moralistic attitude. This attitude enhances the clarity of intellect, and enabling a person with higher vision to visualize the future objectives. The core essence of spirituality is moral values, a broader concept it resembles the objective positive attitude of the human nature with moral ethics. Mind-set of a spiritual individual and Virtue are more or less same, and for this reason, the virtuous person are excellent in their role and responsibility. They also provide effective logical judgment with the informative idea and helps to govern the moral choice made in the context of the daily life practices. It also refers the point to regulate the motivation and ethical conduct in the inner-awareness. Spiritual person conforms their internalized perception of good and excellent spiritualism.

Spiritual Individual practices certain exercise of virtue, which helps in regulate the inner mindset towards their work and internalized regulative ideals. The spiritual individuals hunt for the higher purpose, selfrealization and transcendental values in their workplace, Spiritual individual always focuses on the wholeness to maintain clear aspect of goal and create the openness for self- awareness and the divine involvement as a holistic working environment which directly benefits the outcome of the organization with higher productivity and profitability.

\section{CONCLUSION}

Spirituality, frame's generous of being deeply associated with inner-self. Connectivity with spiritual values and principles helps to trigger the moral fascination of an individual and can contribute the deeper understanding regarding various ethical issues arising in the business context. Spirituality in business dynamism is one of the most enthusiastic signs that business institutions are becoming powerful in today's world.

Finally, this paper concludes that the spirituality has become the life-support for the business in the recent times. People with Spiritual values are entrusted to look beyond owns interest to make a difference in and improvement as a whole. Virtue is also effective for recognizing as well as minimizing the problem of some spiritualism. The forms of Spirituality are generally in four major aspects are self-awareness, innerconsciousness, purpose and ultimate one's concern, that governs the individual's moral values and the reaction during different situations. These moralistic values are exercised over the period of time to generate virtues. Individuals with Spiritual virtue contribute special benefits towards the organizational development. It can thus be winded-up that strategic leaders with their spiritual morality showcases a special frame of information which 
enhances those that are mediated by the leader's for inner development and meta-belief to moderate themselves with the organizational context and style of leadership. It is assumed that this structure can contribute support for the future effort to enhance the multi-dimensional theory of spirituality and leadership.

\section{REFERENCES}

[1] D.P. Ashmos and D. Duchon, "Spirituality at work: A Conceptualization and Measure", Journal of Management Inquiry, Thousand Oaks, 2000, 134-145.

[2] V.M. Kinjerski and B.J. Skrypnek, "Defining spirit at Work: Finding Common Ground", Journal of Organizational Change, 17(1), 2004, 26-42,

[3] K.L. White, "Revolution for the Human Spirit", Organization Development Journal, Chesterland, 19(2), 2001, 47-58.

[4] I.I. Mitroff and E.A. Denton, "A Study of Spirituality in the Workplace", Sloan Management Review, 40(4), 1999, 83-92.

[5] P. Vail, "Introduction to Spirituality for Business Leadership", Journal of Management Inquiry, Thousand Oaks, 9(2), 2000, 115-116.

[6] J. Turner, "Spirituality in the Workplace", CA Magazine, 132(10), 1999, 41-42.

[7] J. Tray nor, "Total Life Planning: A new frontier in work-life benefits", Employee Benefits Journal, 24(4), 1999, 29-32.

[8] P. Grant and P. McGhee, "Spirituality and Ethical Behaviour in the Workplace: Wishful Thinking or Authentic Reality", Electronic Journal of Business Ethics and Organization Studies,132(10), 1999, 41-42.

[9] C. Gulluscio, "Value and CSR in Public Health Sector", Encyclopedia of Corporate Social Responsibility, Springer, 2013.

[10] P.Moitreyee and S. P. Chandra, "Workplace Spirituality -The Essence of Modern Business Organizations", Abhinav National Monthly Refereed Journal of Research in Commerce \& Management, 4(3), 2015, 50-56.

[11] S.K. Chakraborty, "Ethics in Management, Vedantic Perspectives", Oxford University Press $16^{\text {th }}$ Edition, 2013.

[12] http://www.drjohanclaassens.co.za/?p=1243, Retrieved on 18/02/2016.

[13] http://www.visionarylead.org/articles/spbus.htm, Retrieved on 17/02/2016.

[14] http://www.belurmath.org/, Retrieved on 18/02/2016.

[15] http://www.artofliving.org/in-en, Retrieved on 18/02/2016.

[16] http://www.awgp.org/about_us/shantikunj, Retrieved on 18/02/2016. 